\section{THE FORECAST OF THE MONSOON.1}

THE brief telegrams that have lately been published from India concerning the amount of rainfall have given a very uncertain note. Favourable and unfavourable accounts have followed in rapid succession, and at the moment of writing it seems doubtful whether to expect a normal amount of precipitation, or to dread a recurrence of one of those calamitous famines, which drain so severely the resources of India, and from the last of which she has barely recovered. In these circumstances, it is of more than usual interest to turn to the official forecast, to see how the causes, which in the opinion of the best-informed meteorologists affect the climate of India, are operating for and against the prospects of a successful harvest.

At the outset we meet with a grave disappointment. The Simla authorities distinctly express their inability to make a forecast, on any scientific ground, of two very important factors which affect the agricultural value of the monsoon rainfall. These are the possibility of the occurrence of a protracted break in the rainfall during the months of July and August, even after the season has opened favourably, and of an unusually early termination of the rains in the North and Central Provinces of India and in Bengal. For fifteen years the Meteorological Office has deplored the want of the necessary data that would warrant a prediction on these important topics, and there are no signs that the information will be forthcoming at an early date. As a matter of fact, the authorities go little further than an examination of the conditions under which the south-west monsoon currents will arrive on the coasts of the peninsula. It is true that the probable amount of rainfall in the various provinces of India is considered at some length, but it is expressly declared that this "forecast is a statement of probabilities, and not of certainties, and that it is liable to error from the limitation and uncertainty of part of the data on which it is based."

Similar words accompany all the forecasts that prudent men venture to make, and it must be admitted that the continual repetition is wearisome and distressing. Such a caution may be necessary, but if it produces on the mind of an impatient public the impression that little or no advance is being made in meteorology, and particularly Indian meteorology, a great injustice is done to a body of highly-skilled observers, who have not spared themselves to benefit science, to improve the lot of the agriculturist, and to strengthen the hands of the Government in dealing with a misfortune they are eager to alleviate, but powerless to avert.

But it is not difficult to see some of the reasons that compel the staff to halt at the result of this preliminary investigation. Forecasting, as understood in England, and which practically rests on the capacity of the telegraph to outrun the storm or the weather it announces, would be valueless in India. Away from the coasts and outside shipping interests, there is no necessity for daily forecasting, nor for the study of those ephemeral fluctu. ations which go to make up our weather. On the other hand, the meteorological conditions that result from the movement of enormous masses of the air attract greater scientific attention, owing to their periodic character and the effect likely to be produced on agriculture and the well-being of large masses of the population. It would be wrong, however, to forget that in late years, and mainly under the energetic direction of Mr. Eliot, barometric variations, however small in amount, have been studied with good effect, and have revealed the probable existence of cyclical variations which can have

1 "Memorandum on the Snowfall in the Mountain Districts bordering Northern India, and the Abnormal Features of the Weather in India; with a Forecast of the S.W. Monsoon Rains of $1899 . "$ By John Eliot, Meteorological Reporter to the Government of India, and Director-General Observatories in India. (Simla: June 1899.)

No. I 558 , vOL. 60 ] considerable influence in promoting or checking the general oscillatory motion of the air across the equator, to which motion the south-west and north-east monsoon winds are mainly due.

But in the forecast before us, though the variations of pressure from the normal, and the effect such fluctuations have on the local weather existing in India immediately preceding the advance of the monsoon, are treated as a factor in the problem, two other conditions have naturally great weight. These are the amount and time of occurrence of the snowfall in the mountain districts adjacent to Northern India, and the behaviour of the south-east trades in the preceding season, as investigated at Seychelles, Mauritius, the Cape of Good Hope, and the logs of ships passing over the area affected. Such latter information is of necessity incomplete, but is likely to be of great importance in proportion as it covers a larger area, for the greater the district brought under review, the greater the probability of tracing the true physical cause on which important variations rest. It may not be out of place, as showing the wide extent over which meteorological phenomena extend themselves, and the consequent necessity for the examination of all remote causes to which they may be traced, to recall the apparent connection existing between the barometric oscillations in the Indo-Malayan region on the one hand, and Russia and Siberia on the other. Further, we have some evidence of connection between the south-east rains of South Africa and the amount of the rainfall at the time of the summer monsoon, while the overflow of the Nile seems to participate in similar periodic variations. Such general disturbance tends to point to a common cause, and it is gratifying to know that the possibility of the connection has been pointed out by the Indian meteorological officers, who are fully alive to the importance of discovering the origin of these effects, which demonstrate themselves periodically. In basing the forecast on more or less local appearances, we seem to recognise the weak point in long-period forecasting. We are in the position of a physician who deals with the symptoms rather than the origin of a disease.

This difficulty of trusting to appearances may be illustrated in many ways. For instance, how are we going to estimate the relative importance of the two operating factors we have mentioned above, the snowfall on the Himalayas and the behaviour of the south-east trades? And how are we going to act if we find the indications from the two sources discordant? Some time since we believe that the snowfall was regarded as the one important item in the making up of the forecast. Scanty rain was anticipated as the consequence of heavy snow, but greater experience has somewhat discredited the notion. Late snow in April or May, or the cause which produces the late snowfall, no doubt does exercise very considerable influence locally on the distribution of the monsoon winds; but when we have to deal (as already pointed out) with the effects produced by the circulation of an atmosphere covering an entire hemisphere, such local results play but an insignificant part. Nevertheless, we find Mr. Eliot, who doubtless is glad to avail himself of every source of information, carefully tabulating the time and amount of the snowfall from Afghanistan on the West to Assam in the East. But, in drawing his conclusion, he does not leave out of sight the local character of the indication, and a distinction is drawn between the conditions that should follow the reports from Western India and those received from the Eastern Himalayas. In the former case, the signs point to an early and strong monsoon with beneficial results to the utmost limits of the Punjab. The conclusions to be drawn from the accounts from the eastern portion are more uncertain both on account of deficiency in the data received and greater doubt in the interprecation of the sign, but it is expected that the rainfall in North-east India will be diminished, 
while heavier rain will be prevalent in the north-west. It'will be interesting to compare this prediction with actual results; but at present we are more concerned to point out the care that $s$ taken in preparing the forecast, the difficulty in the collection of exact data, and the manful determination to make the best use of all available sources.

This scrupulous care is well illustrated in the second class of information incorporated into the weather prediction, and which rests on the abnormal features of the recent meteorology of India. To discuss these with any prospect of success, it is first necessary to determine correct normals. The work that this involves can only be appreciated by those who have been actually concerned in a similar inquiry, but it is a method of investigation into which $\mathrm{Mr}$. Eliot and his predecessor, Mr. Blandford, have thrown themselves with signal success. The volumes of the Indian Meteorological Memoirs bear witness to the ability and zeal with which the work has been carried on throughout some twenty-five selected observatories. We may well express the hope that so much work is now yielding abundant fruit.

\section{THE PRESENT POSITION OF THE INVES-} TIGATION OF THE MALARIAL PARASITE.

$\mathrm{T} \mathrm{HE}$ rôle played by the mosquito as a carrying agent of the malarial parasite from man to man seems to be restricted to one genus, the Anopheles. Major Ross, of the Liverpool School of Tropical Diseases, in a telegram from Sierra Leone, announces the fact that he has found the Anopheles there, and that it may be the intermediary host of the quartan malarial fever.

Many observers in different countries, noticing the fact that malaria is most prevalent at the most active period of mosquito life, have attributed malaria to the agency of this insect. Dr. Patrick Manson, in 1894, first brought the subject forward in England, and, acting on his suggestion and advice, Major Ross undertook an investigation in India.

In I 897 , by using two species of Anopheles, Ross traced the malarial parasite into the wall of the stomach of the mosquito after it had fed on patients whose blood contained the crescentic gametocytes; the next year he succeeded in tracing the complete life-history of the proteosoma Grassii Labbé of sparrows, and showed that its intermediary host was one particular kind of mosquito, the Culex pipiens. The gametocytes contained in the red blood corpuscles of the vertebrate host pass with the blood into the stomach of the mosquito, and passing through the stomach-wall bulge into the body-cavity; here a sexual process takes place, zygotoblasts are eventually formed, which pass into the insects' blood, and finally find their way into the salivary gland and to the duct leading from this to the extremity of the stylet; from here they escape into the blood of the vertebrate host when the insect bites. A full account of the process is given by Ross in NATURE of August 3 .

Following on these results, Grassi in Italy attacked the problem from another point of view; he studied the mosquitoes prevalent in the different parts of the country where malaria occurs. The results were interesting. He found there was no indigenous malaria where the Culex pipiens was common, but it did occur where the large mosquito Anopheles was found.

Bignami and Bastianelli, who had been trying unsuccessfully to infect a man by allowing mosquitoes to bite him, attributing their want of success to the use of the wrong kind of mosquito, and, acting on the observations of Grassi, tried again with some mosquitoes imported from a malarious district. This time they succeeded in infecting the man with malaria of the same type that prevailed in the district from which the mosquitoes came. More- over, they have shown that the development of the human form of parasite in the body of Anopheles is identical with the development of the proteosoma of birds in Culex pipiens, as observed by Ross.

According to these observers, the species Anopheles claviger is the most common intermediary host of the parasite of malaria in Italy, the tertian and summerautumn types.

It is evident that the next step in the study of malaria should be to hunt for the different species of Anopheles and see if these are the intermediary hosts of the different types of malaria throughout the world, and what particular species is most concerned in transferring the parasite from man to man. Grassi has done this for Italy, and now we hear that Ross has found a species of Anopheles to be concerned in the transference of quartan fever; thus all the types of malarial fever are now referred to the Anopheles as their intermediary host. His full report on return from Africa will be read with interest.

Whether the Anopheles can be extirpated from a locality, and by what means, will be the problem for scientific workers resident abroad to settle ; fortunately they seem to be confined to small areas, so the suggestion of Ross to draw off the water from stagnant pools may not be so hopeless a task as it would at first appear.

\section{NOTES.}

THE following men of science have been elected fellows of the Reale Accademia dei Lincei. As ordinary fellows : for mathematics, P. Tardy, G. Veronese; for mechanical science, G. Favero, G. Colombo, V. Volterra; for agricultural science, A. Targioni-Tozzetti. As corresponding fellows : for mathematics, G. Ricci ; for mechanics, G. A. Maggi ; for physics, G. Grassi, A. Battelli ; for crystallography and mineralogy, A. D'Achiardi ; for botany, F. Delpino; for agriculture, A. Borzi ; for pathology, E. Marchiafava. As foreign fellows : for mathematics, G. Mittag-Leffler, J. Weingarten; for physics, E. Mascart, W. Kohlrausch ; for chemistry, Ludwig Mond, E. Fischer ; for crystallography and mineralogy, C. Klein, F. Fouqué, F. Zirkel; for geology and palæontology, O. Torell, A. De Lapparent, R. Lepsius ; for botany, W. Pfeffer ; for zoology and morphology, E. Haeckel, E. van Beneden; for physiology, E. Pfliger, E. Hering.

THE Berlin correspondent of the Times reports that the Imperial Government has ordered Prof. Kossel, of the Board of Health, to proceed to Lisbon and Oporto to study the plague and the methods adopted to combat it. Prof. Kossel will be accompanied by Prof. Frosch, of the Berlin Institute, for the Study of Infectious Diseases, who is being despatched on the same mission by the Prussian Government. Drs. Calnette and Salinbeni are already investigating the outbreak, and will report upon it to the Paris Pasteur Institute.

PRINCE KROPOTKIN sends us a note which suggests that the movements of sea-gulls along the British coasts may indicate forthcoming weather changes. On Saturday, August 26, while off Broadstairs, he noticed several flocks of gulls flying along the coast towards Dover. The wind was then blowing from the north-east, as it had been doing throughout August, and there was little indication of a change; but an old fisherman remarked that the gulls which had stayed on the coast at Margate and to the west of it were moving to the south coast to meet a south-west wind, which was sure to come. As is known, the change occurred on the following day, and the wind veered round to the south-west. In connection with this observation, it is worth remark that $\mathrm{Mr}$. Inwards, in his "Weather Lore," says: "The arrival of sea-gulls from the Solway Firth to Holywood, Dumfriesshire, is generally followed by a high wind and heavy rain from the south.west." 